\title{
Low Speed Protection Methodology for a Symmetrical Monopolar HVDC Network
}

\author{
Geraint Chaffey, Tim C. Green \\ Electrical and Electronic Engineering Department \\ Imperial College London \\ London, UK \\ Email: g.chaffey12@imperial.ac.uk
}

\begin{abstract}
Protecting a future HVDC network from short circuit DC faults is presently expected to require extensive implementation of fast HVDC circuit breakers, allowing for rapid fault isolation. The requirement for circuit breakers may, however, be reduced or removed depending on the protection methodology, resulting in a slower post-fault recovery. The expected fault response and the subsequent network recovery is dependent on the circuit breaker, network, and converter configurations. This paper examines a low speed protection methodology for a symmetrical monopolar HVDC system, a configuration which requires pole to pole balancing following a pole to ground fault. The fault clearance and network recovery timings are therefore evaluated for both pole to pole and pole to ground faults on several case study networks.
\end{abstract}

\section{INTRODUCTION}

An increase in renewable energy generation leads to a desire for increased levels of interconnection to allow for international sharing of energy from disparate and individually variable energy sources. Further HVDC systems are anticipated to provide this capacity, and whilst existing connections mostly consist of point to point connections, constructing a multiterminal network is expected to bring both economic and operational advantages. The protection of such a system, however, is still in its infancy, and provides a challenge for the network designer.

The preferred AC to DC converter for HVDC applications is the Half-Bridge Modular Multilevel Converter (HBMMC), which allows for efficient and flexible operation with a small footprint. The HB-MMC, however, is sensitive to low impedance DC-side faults, and feeds an uncontrolled fault current that requires isolation by external equipment. In existing point to point connections this isolation is performed using the circuit breaker at the $\mathrm{AC}$-side of the converter, however when considering multiterminal systems this method is expected to lead to unacceptable delays in recovering the healthy network elements and alternative protection methods are anticipated.

Isolating a DC current is challenging as there is no natural current zero crossing, therefore one must be synthesised to allow for isolation by a mechanical contact. Mechanical and power electronic hybrid ('hybrid') HVDC circuit breakers have

The authors gratefully acknowledge the funding and support of EDF R\&D and the EPSRC through the industrial CASE scheme. been recently prototyped by industry [1]-[3], however their implementation on a network is yet to be established. Auxiliary switchgear is also typically present in an HVDC system for purposes of isolation, reconfiguration and protection [4]. One such element, the transfer switch, is able to commutate a load current, but at a slower speed than typically required for protection of a DC fault. An example device from the literature can isolate a $5.3 \mathrm{kA}$ current in $30 \mathrm{~ms}$ [5]. Whilst the hybrid HVDC circuit breaker is expected to be functional, the economic cost will be high, therefore it is interesting to look at ways to minimise the requirement for circuit breakers.

Additional energy diverting converters are sometimes implemented on wind farm connections to dissipate excess energy and prevent overvoltage in the event of an AC network outage, sometimes termed a 'DC chopper'. There are several topologies proposed, with either simple series switch or modular topologies [6], with some topologies proposed in a bipolar arrangement which would allow the correction of pole to pole imbalance [6], [7]. There may also be a limited requirement for such devices in a network scenario [8].

There have been several protection schemes already proposed in the literature [9]. It is commonly considered that circuit breakers would be required at each end of each cable to provide appropriate protection [2], [10], [11]. Alternative schemes have however been outlined which use fault blocking converters [12]-[14], apply circuit breakers or DC/DC converters to separate the network into zones [10], [15], or otherwise use a reduced number of circuit breakers [16]. Fig. 1 shows two strategies - a circuit breaker at each end of each cable ('line protection', Fig. 1a) and one circuit breaker protecting each converter, with cable isolation provided by transfer switches ('converter protection', Fig. 1b).

There are several choices of converter and cable arrangement when designing an HVDC system. When using a single converter (monopole), it is common to use a bipolar cable arrangement in which each cable is charged to half the converter DC-side voltage, due to advantages in isolation and voltage ratings of high voltage components. Using a bipolar converter arrangement brings redundancy advantages, and may be more attractive for higher power connections. A monopolar converter is not normally able to independently control the current on each pole without additional equipment [17]. Fol- 
lowing a pole to ground fault, the faulted pole discharges into the fault, whilst the healthy pole remains charged. Considering the case of a monopolar converter with a symmetrical bipolar cable arrangement (a symmetrical monopole), the converter is not able to recharge just the discharged pole, but instead any current adds charge equally to both poles. An external method of discharging the healthy pole may therefore be required.

The protection scheme implemented on a future network is dependent on many factors, both technical and economic. Low speed methods may offer viable protection at a lower economic cost, depending on the strength of the connected $\mathrm{AC}$ systems and the outage duration. This paper therefore examines the timings associated with a low speed protection method on an HVDC network with symmetrical monopolar converter stations.

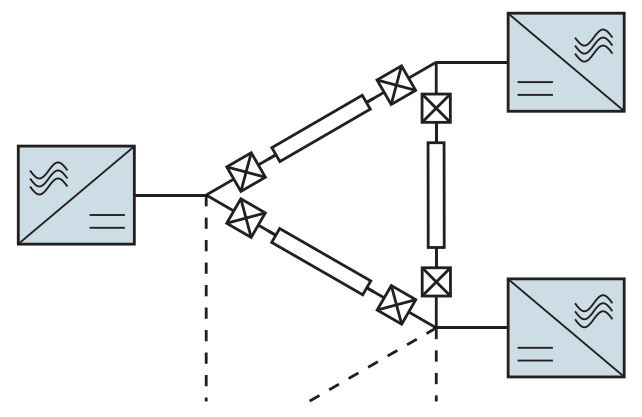

(a) Line protection

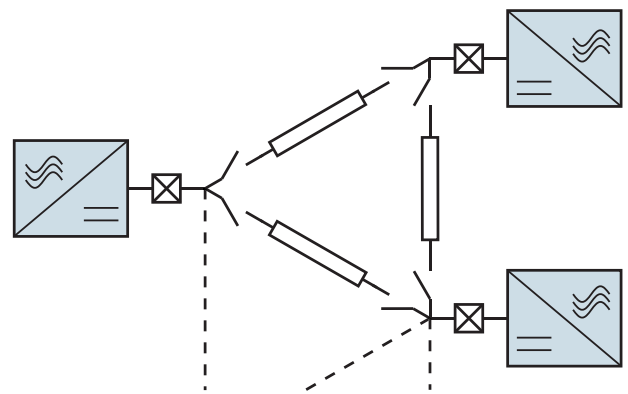

(b) Converter protection with transfer switches for line isolation

Fig. 1: Example protection strategies

\section{Modelling OF HVDC Systems}

To evaluate transient fault conditions on HVDC systems, models of converters and cables have been developed in the Matlab/Simulink enviroment. Symmetrical monopolar HBMMCs are modelled with 100 submodules per arm, each with a capacitor at a nominal $10.5 \mathrm{kV}$. Each HB-MMC arm is implemented using OPAL-RT ARTEMiS models. Converter stations are specified to maximise a bipolar arrangement of the highest power cable at the time of writing [18], therefore are rated to $2600 \mathrm{MW}$ and $1050 \mathrm{kV}$ pole-to-pole at the DCside. Each converter is grounded through a high impedance star reactor at the converter side of the interface transformer, as is observed on existing systems [19], [20]. Arm inductors

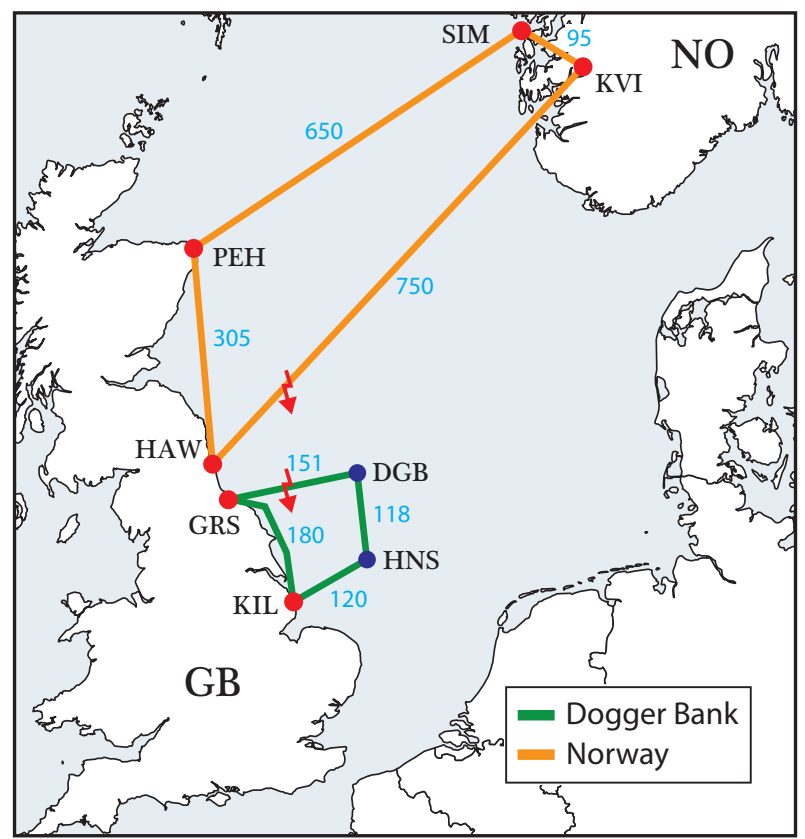

Fig. 2: Example four terminal North Sea network topologies. Cable lengths marked in kilometres.

are specified to $0.1 \mathrm{pu}$ and no concentrated energy storage is required for filtering at the DC-side of the converter. Submodule bypass thyristors are present and are activated when an overcurrent or under voltage event is detected. The peak AC voltage is specified to be $95 \%$ of the nominal DC voltage. Cables are specified using estimated parameters for XLPE cable [21], extrapolated for $525 \mathrm{kV}$ cable [12], and modelled using a wideband (frequency dependent phase mode) cable model within the OPAL-RT ARTEMiS SSN environment.

Modular circuit breakers are modelled with 10 submodules, each with bidirectional IGBTs with snubbers and a varistor element with a protective voltage of 1.5 times the nominal. The varistor elements are specified based upon the characteristic in [22]. The action of a hybrid circuit breaker is emulated using a $3 \mathrm{~ms}$ delay between fault detection and circuit breaker operation. The circuit breaker can be controlled in a current limiting mode by inserting a fraction of its varistors; the control and energy requirements for this mode are further discussed in [23]. In this paper, where used, the current is constrained to $3 \mathrm{kA}$. Fault detection is performed at each node without communication.

An energy diverting converter in a bipolar configuration is implemented on each network to allow balancing during pole to ground fault scenarios. Each energy diverting converter pole consists of a resistor, inductor, and IGBT that is controlled using a PWM controller allowing for control based on current and/or voltage. The default control mode for the energy diverting converter as implemented is to conduct a $2 \mathrm{kA}$ current when there is a pole to pole voltage imbalance.

Two four terminal networks are evaluated, representative of potential future North Sea systems, Fig. 2. The first network 


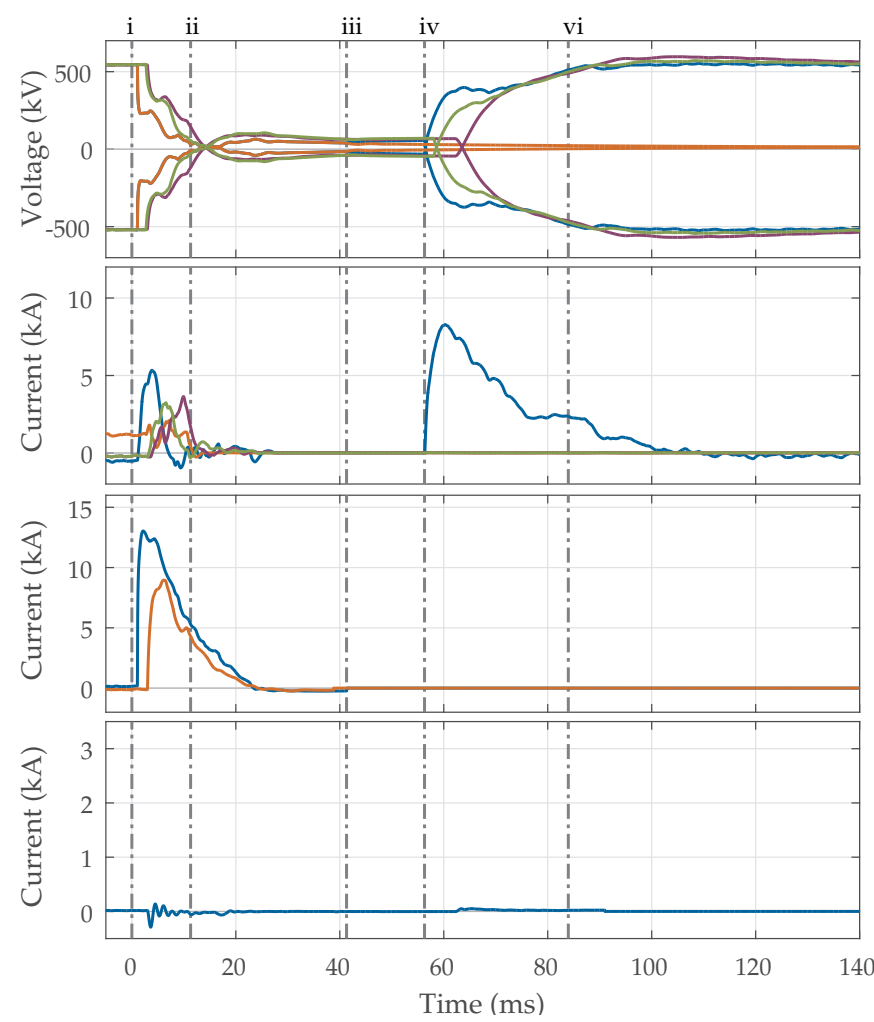

Fig. 3: Pole to pole fault and recovery on the Norway network uncontrolled recharge. Top to bottom: cable voltages, converter DC-side currents, transfer switch currents for the faulted cable, energy diverting converter current. Time markers: (i) fault inception, (ii) transfer switch operates, (iii) transfer switch isolates, (iv) converters notified fault cleared, (v) poles balanced, (vi) network recharged.

connects offshore wind generation in the Hornsea (HNS) and Dogger Bank (DGB) areas to the Great Britain (GB) transmission system at Greystones (GRS) and Killingholme (KIL), whilst the second network provides interconnection between Peterhead (PEH) and Hawthorn Pit (HAW) on the GB system and Kvilldal (KVI and Simadalen (SIM), Norway (NO) through two proposed connections, with two additional cables to create a meshed network. Each node on each network is a 2600 MW symmetrical monopolar HB-MMC station. The faults simulated in this paper are low impedance short circuits $200 \mathrm{~km}$ from HAW on the HAW-KVI cable, and $40 \mathrm{~km}$ from GRS on the GRS-DGB cable. It is noted that whilst the networks shown are presented for context and to show networks of reasonable scale, no claims are made to the economic feasibility of such a system or to the viability of connection to the $\mathrm{AC}$ systems at these points.

\section{Low Speed Protection Methodology}

The most commonly considered HVDC protection strategy uses a circuit breaker at each end of each cable, each with an additional inductance. The protection methodology under examination in this paper uses a reduced number of circuit

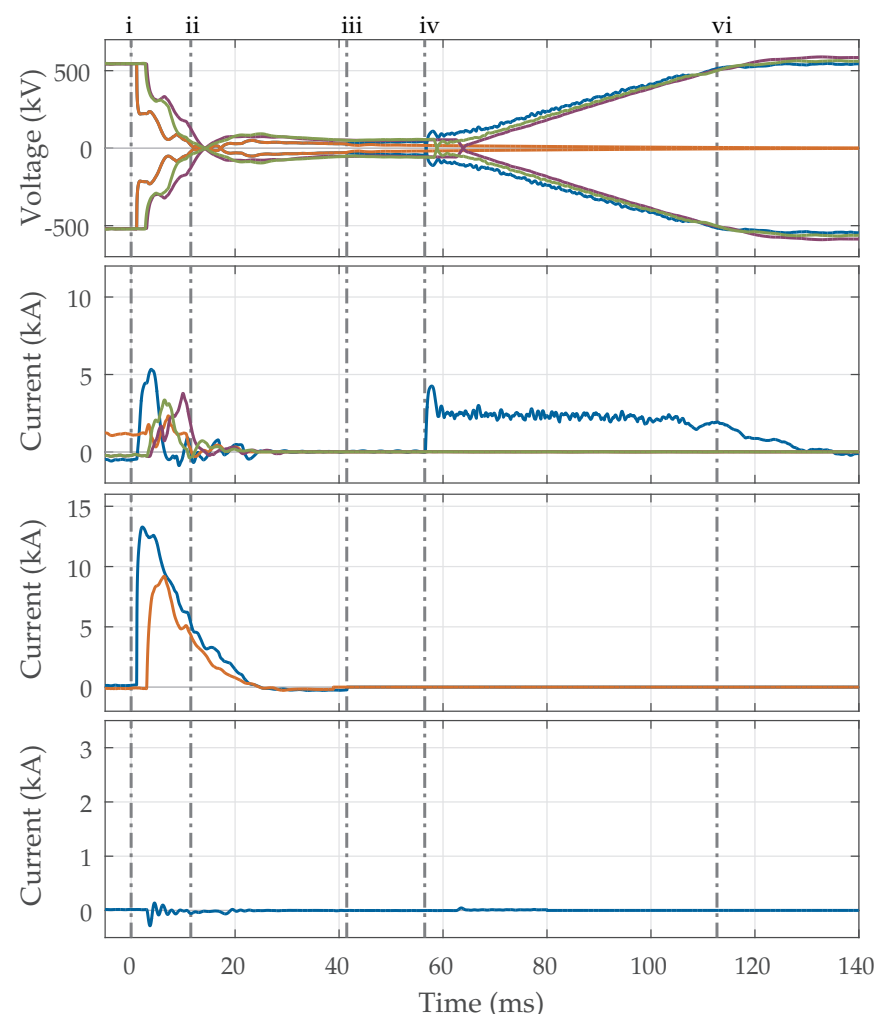

Fig. 4: Pole to pole fault and recovery on the Norway network - controlled recharge. Plots and time markers as in Fig. 3.

breakers - one at each converter terminal, with a $50 \mathrm{mH}$ inductance at the converter terminal to limit the rate of rise of fault current, and no other additional inductance across the network. In the event of a fault, each circuit breaker provides isolation of the local HB-MMC based upon local measurements. The cables across the network discharge into the fault, resulting in a large discharge current. Following the HB-MMC isolation and the capacitive cable discharge, the current decays towards zero. Transfer switches are then able to isolate the faulted cable section once the current decays below the operational threshold, in this case $5.3 \mathrm{kA}$, and the isolation is completed after a $30 \mathrm{~ms}$ operation time. Successful isolation from each of the transfer switches is communicated to all circuit breakers, which provide a reclosing operation to recharge the network following a $15 \mathrm{~ms}$ communication delay. The circuit breaker either recloses, resulting in an uncontrolled recharging current, or acts in a current limiting mode to control the cable recharging current. Following the recharging of the healthy cable sections, the fault is cleared and power flow can resume.

\section{Pole to Pole Fault}

The response of the Norway case study network to a pole to pole mid-cable fault is shown in Fig. 3. It is observed that the voltage across the network falls, and the converter stations feed fault current into the fault. The circuit breaker at each converter isolates the fault following local detection. At time marker 


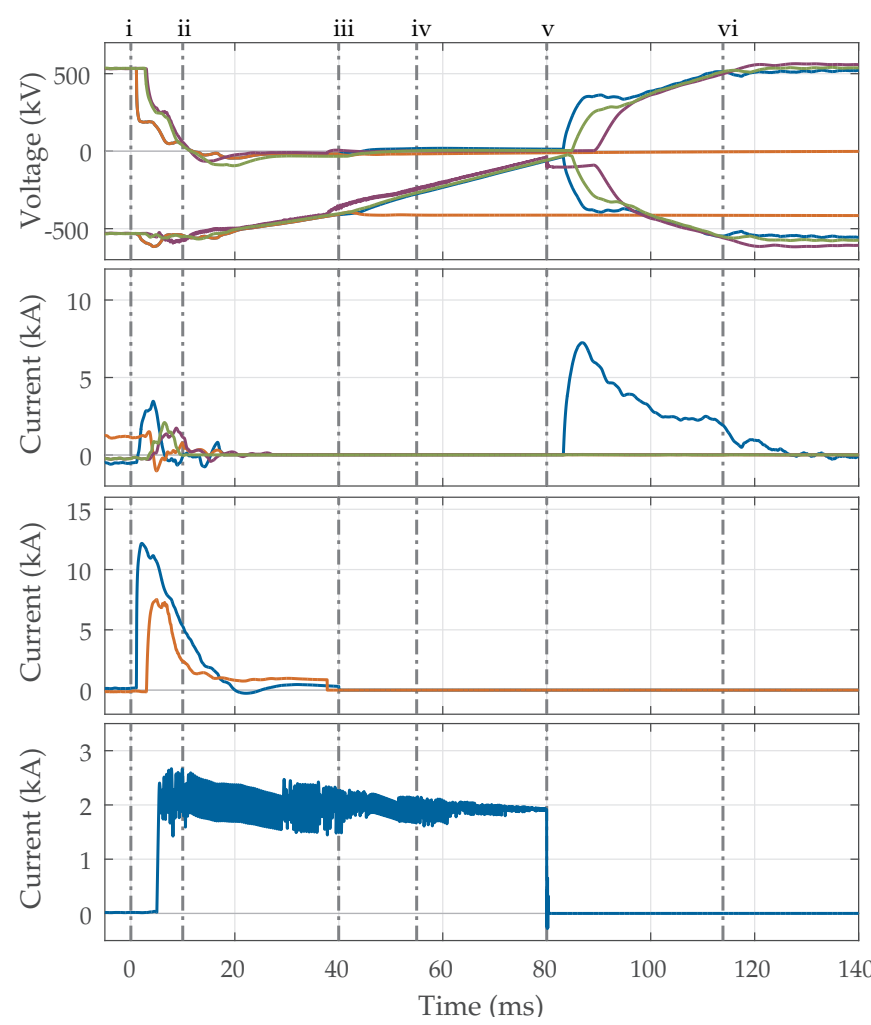

Fig. 5: Pole to ground fault and recovery on the Norway network - uncontrolled recharge. Plots and time markers as in Fig. 3.

(ii) the current decays below the transfer switch operational threshold, and the transfer switch begins to operate, which is completed at (iii). Following a communication delay, the converters are notified that the fault is cleared (iv) and the circuit breakers are reclosed, allowing an uncontrolled recharging current, after which the network recharging is completed (vi). The uncontrolled current during this recharging phase exceeds the allowable IGBT current and the submodule bypass thyristors would be required to operate in this scenario.

Recharging a network using an uncontrolled current presents a severe event to the converter, which may be unattractive to the operator. Recently proposed circuit breakers can provide a current limiting function, therefore it is possible to limit the recharging current, with a penalty of increased energy dissipation requirements in the circuit breaker [23]. Fig. 4 shows the operation of the current limiting circuit breaker during the network recharge, leading to an increase in the recharging time, and therefore a longer total post-fault recovery time.

\section{Pole to Ground Fault}

During a pole to ground fault, the healthy pole remains charged, whilst the HB-MMC naturally rectifies the AC-side voltage and therefore feeds a current until the DC-side of the converter is of the same magnitude as the peak $\mathrm{AC}$ voltage, given that the converter has a high impedance ground. Given that the faulted cable is grounded by the fault, the

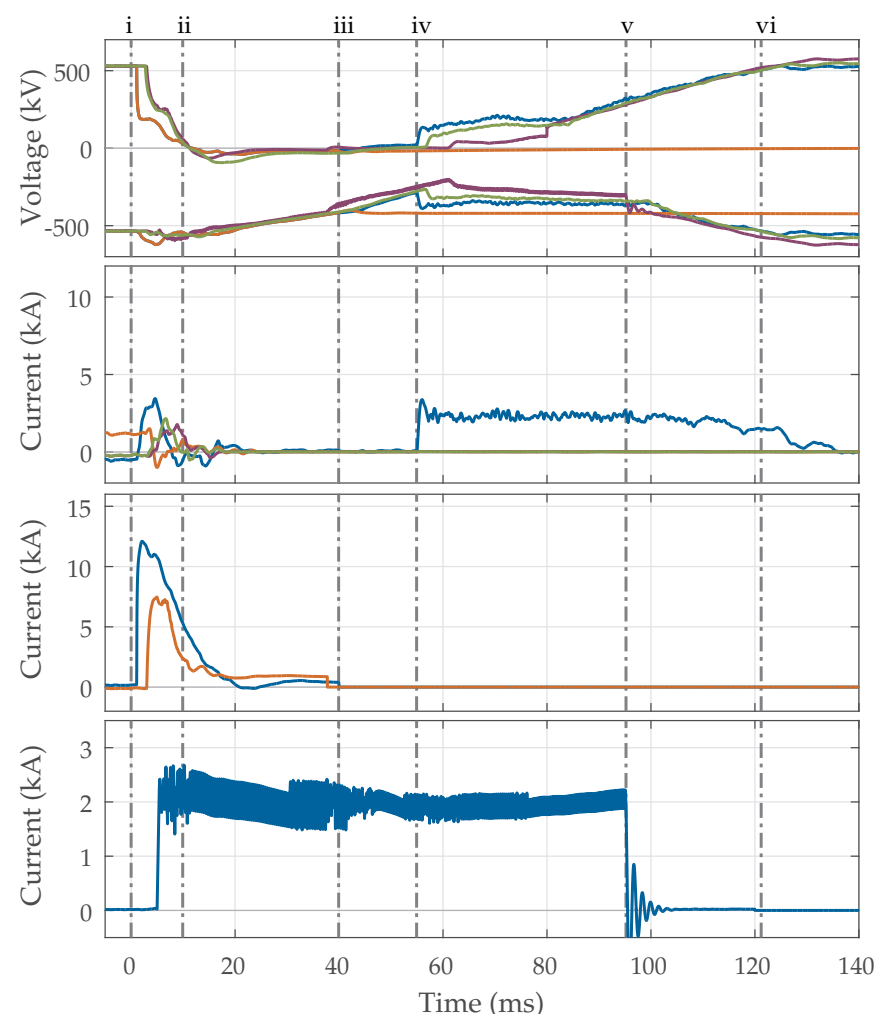

Fig. 6: Pole to ground fault and recovery on the Norway network - controlled recharge. Plots and time markers as in Fig. 3.

fault current through the converter charges the healthy cable pole. The circuit breaker at each terminal isolates the fault within $4 \mathrm{~ms}$ of fault detection. The voltage rise on the healthy pole due to converter fault infeed depends on the ratio of fault feeding converters to the cable capacitance - the current (and therefore charge imparted to the cable) is dependent on the fault location and system inductance, whereas the voltage increase is proportional to the charge and inversely proportional to the cable capacitance. A higher voltage rise is therefore observed on a network with less cable length.

The pole to pole balancing operation can be conducted simultaneously with the operation of the transfer switch. Fig. 5 shows the operation of the Norway network following a pole to ground fault. A $2 \mathrm{kA}$ energy diverting converter is applied to balance the poles. Following fault isolation by the transfer switches, the converter stations wait until the network is balanced before recharging the network, therefore there is an additional balancing delay when compared to the pole to pole fault case.

Recharging of the network can take place at the same time as the balancing operation, as long as the network is not charged too fast which would result in a cable overvoltage. This operation requires a current limiting circuit breaker to allow a controlled recharging current. This circuit breaker is able to regulate the current, and monitor the voltage to ensure that no cable overvoltage occurs. This operation is shown in 


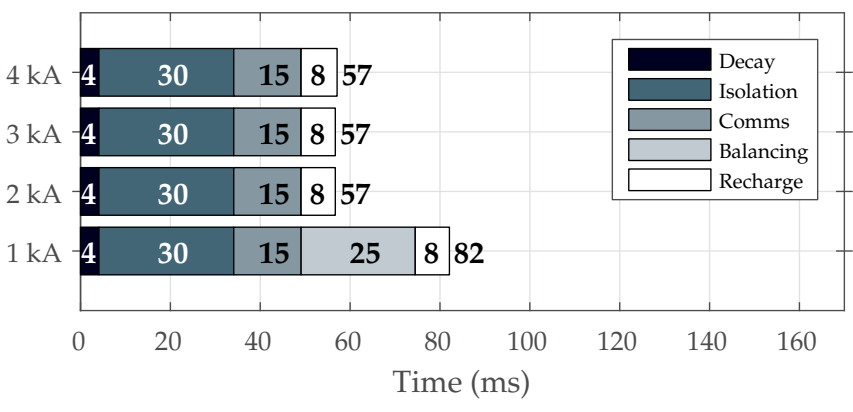

(a) Dogger Bank network

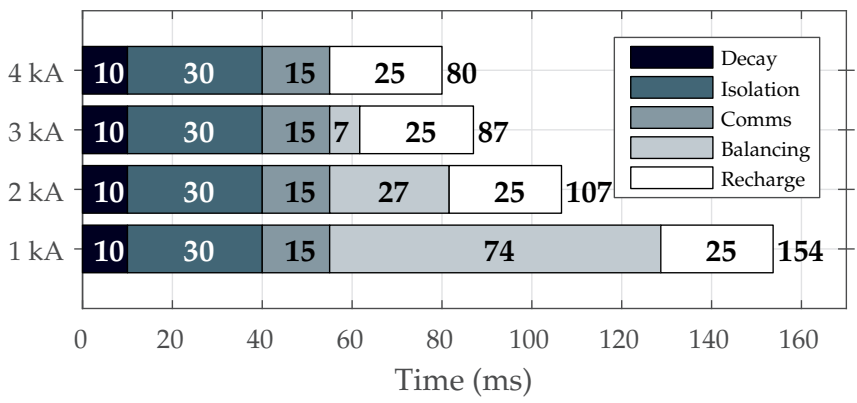

(b) Norway network

Fig. 7: Impact of energy diverting converter rating on post fault recovery times, with one recharging converter

Fig. 6.

\section{COMparison of CASE Study Networks}

Whilst the two study networks have the same number of converters and cables, the cable length varies significantly, from $569 \mathrm{~km}$ on the Dogger Bank network to $1800 \mathrm{~km}$ on the Norway network ( $115 \mu \mathrm{F}$ to $364 \mu \mathrm{F}$ per pole). The larger network therefore takes longer to recharge following a fault, and longer to balance following a pole to ground fault.

\section{A. Energy Diverting Converter Rating}

The influence of the energy diverting converter rating is examined in Fig. 7. It is shown that for the Dogger Bank network, Fig. 7a, a $1 \mathrm{kA}$ rating results in a delay due to balancing taking $25 \mathrm{~ms}$ longer than the fault isolation procedure, whilst for a rating of $2 \mathrm{kA}$ or more, there is no delay to the network recovery. Conversely, for the Norway network, Fig. 7b, a $1 \mathrm{kA}$ rating leads to a $74 \mathrm{~ms}$ delay, and for no delay an energy diverting converter with a $4 \mathrm{kA}$ rating would be required. Note that this could be achieved using more than one energy diverting converter if required.

\section{B. Composition of Recovery Timings}

The composition of the post fault recovery timings for both case study networks are shown in Fig. 8. Considering the Dogger Bank network, Fig 8a, the timings for the pole to pole and pole to ground cases are similar, given that the balancing takes place in the period of fault isolation and communication, therefore does not delay the recovery.
The controlled recharging takes significantly longer than the uncontrolled, due to the slower rate of charge imparted on the cable.

Considering the Norway network, the impact of the larger cable length is evident - assuming the same $2 \mathrm{kA}$ energy diverting converter, the discharging takes significantly longer than in the Dogger Bank case and therefore delays the total post fault network recovery time.

In general, the pole to pole fault cases take longer for the fault current to decay below the transfer switch operational threshold, due to the increased fault current contribution from the converter in these cases. It is observed that in the fault scenarios studied, the Dogger Bank network can be recovered following a fault in $57 \mathrm{~ms}$ to $80 \mathrm{~ms}$, whilst the Norway network can be recovered following a fault in $84 \mathrm{~ms}$ to $119 \mathrm{~ms}$. The larger cable length of the Norway network leads to a longer cable discharge decay and also a longer recharging time, therefore it is suggested that larger networks might lead to longer required recovery times.

\section{OUTLOOK FOR FAULT BLOCKING CONVERTERS}

The simulation results in this paper examine a network with HB-MMCs, which require an external circuit breaker to isolate the fault. Research and development into converters that can control the current into a DC-side fault is maturing, therefore future HVDC systems may consist of both fault feeding and fault blocking converters. The protection schemes discussed in this paper would be easily achievable using fault blocking converters, and would not require any circuit breakers to provide the same functionality.

\section{CONCLUSION}

Fast hybrid circuit breakers and associated current limiting inductances are expected to have a large volume and economic cost. A low speed protection method aiming to reduce the reliance on fast circuit breakers has been examined. It has been shown that using a limited number of circuit breakers and transfer switches to isolate faulted cables, a network can be recovered in the $60 \mathrm{~ms}$ to $120 \mathrm{~ms}$ time-scale for the study networks and fault cases examined. Isolation equipment such as a transfer switch is expected to be required in any case, therefore this configuration represents a decrease in the required protective equipment on the network. Additional inductance is also not required at the cable terminals. The exact recovery time is dependent on the balancing capability during a pole to ground fault, and the recharging characteristic which is dependent on the allowable converter recharging current, and the application of current limiting circuit breakers. The HVDC system may therefore be protected at a lower economic cost, if the momentary outage were acceptable from the perspective of the connected AC transmission systems. It has also been shown that network topology could lead to significant differences in the recovery characteristics, and in particular it is suggested that larger networks could lead to a longer recovery time, therefore further topologies should be examined in detail. 


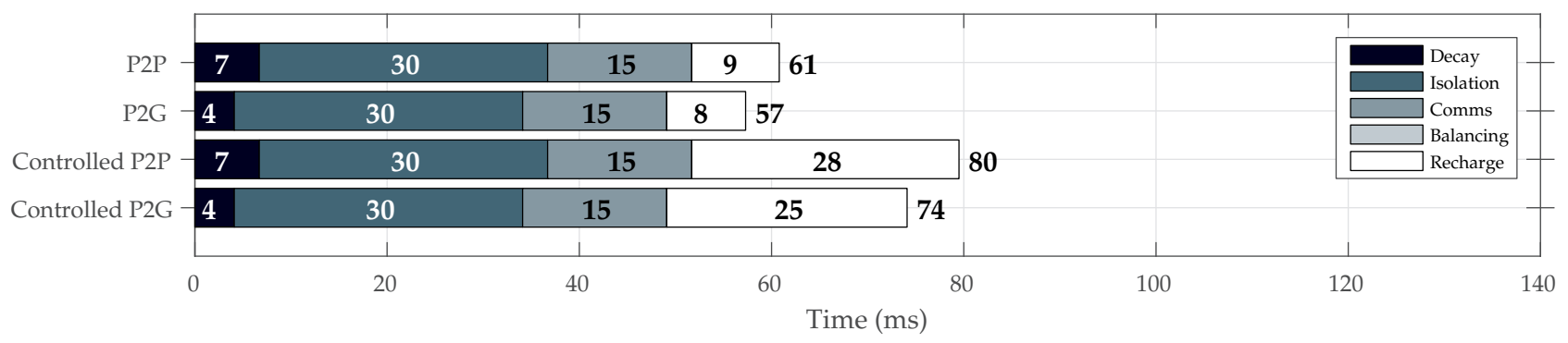

(a) Dogger Bank network

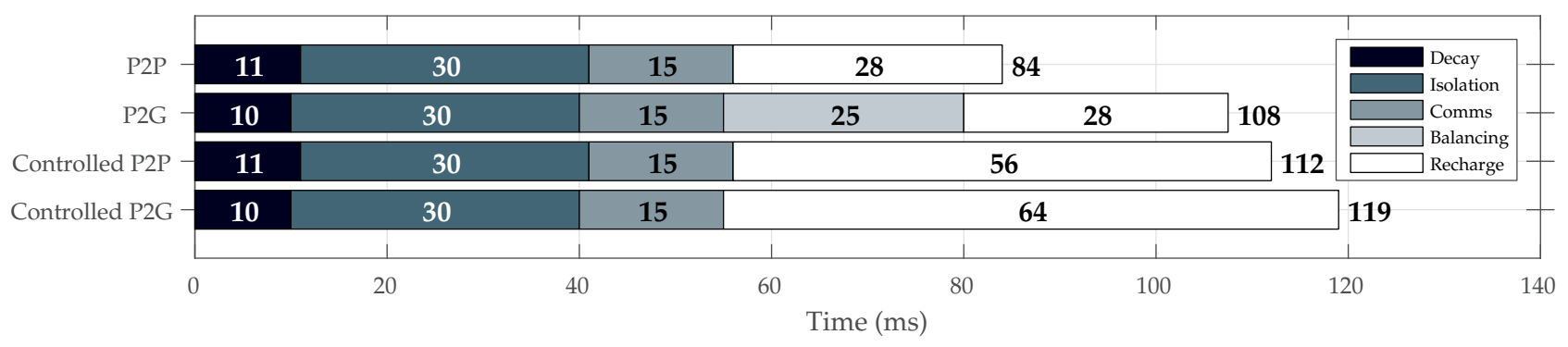

(b) Norway network

Fig. 8: Composition of post fault recovery time for pole to pole (P2P) and pole to ground (P2G) faults, without and with the use of current limiting at the circuit breaker

\section{REFERENCES}

[1] W. Grieshaber, J.-P. Dupraz, D. L. Penache, and L. Violleau, "Development and test of a $120 \mathrm{kV}$ direct current circuit breaker," CIGRE session 2014, 2014.

[2] M. Callavik, A. Blomberg, J. Häfner, and B. Jacobson, "The Hybrid HVDC Breaker," ABB grid system, Technical paper Nov, 2012.

[3] W. Zhou, X. Wei, S. Zhang, G. Tang, Z. He, J. Zheng, Y. Dan, and C. Gao, "Development and test of a $200 \mathrm{kV}$ full-bridge based hybrid HVDC breaker," in Power Electronics and Applications (EPE'15 ECCEEurope), 2015 17th European Conference on. IEEE, 2015, pp. 1-7.

[4] JWG A3/B4.34, Technical Brochure: Technical requirements and specifications of state-of-the-art DC switching equipment. CIGRE, Under Review.

[5] C. Peng, J. Wen, W. Xiuhuan, Z. Liu, Z. SHEN, and K. YU, "Development of DC Transfer Switch in Ultra High Voltage DC Transmission Systems," Proceedings of the Chinese Society for Electrical Engineering, vol. 16, p. 020, 2012.

[6] J. Maneiro, S. Tennakoon, C. Barker, and F. Hassan, "Energy diverting converter topologies for HVDC transmission systems," in Power Electronics and Applications (EPE), 2013 15th European Conference on. IEEE, 2013, pp. 1-10.

[7] N. Okaeme, D. Trainer, and C. Davidson, "Control circuit," Jan. 13 2016, EP Patent 2,820,734. [Online]. Available: https://www.google.com/patents/EP2820734B1?cl=en

[8] C. Nentwig, J. Haubrock, R. H. Renner, and D. V. Hertem, "Application of DC choppers in HVDC grids," in 2016 IEEE International Energy Conference (ENERGYCON), April 2016, pp. 1-5.

[9] W. Leterme and D. Van Hertem, "Classification of Fault Clearing Strategies for HVDC Grids," in Across borders - HVDC systems and markets integration: CIGRE Lund, 2015.

[10] F. Dijkhuizen and B. Berggren, "Zoning in high voltage DC (HVDC) grids using hybrid DC breaker," in Proc. EPRI HVDC and FACTS Conf., Palo Alto, USA, 2013, pp. 1-8.

[11] J. Marvik, S. D'Arco, and K. Sharifabadi, "Protection scheme for multiterminal radial VSC HVDC system without communication between terminals," in Across borders - HVDC systems and markets integration: CIGRE Lund, 2015.
[12] G. Chaffey and T. C. Green, "Reduced DC Circuit Breaker Requirement on Mixed Converter HVDC Networks," in PowerTech (POWERTECH), 2015 IEEE Eindhoven, June 2015.

[13] C. Barker, R. Whitehouse, A. Adamczyk, and M. Boden, "Designing fault tolerant HVDC networks with a limited need for HVDC circuit breaker operation," B4-112, CIGRE, 2014.

[14] C. Petino, M. Heidemann, D. Eichhoff, M. Stumpe, E. Spahic, and F. Schettler, "Application of multilevel full bridge converters in HVDC multiterminal systems," IET Power Electronics, vol. 9, no. 2, pp. 297304, 2016.

[15] C. E. Sheridan, "Assessment of HVDC Technologies for an Offshore MTDC Grid," Ph.D. dissertation, Imperial College London, 2015.

[16] M. Hajian, L. Zhang, and D. Jovcic, "DC Transmission Grid With Low-Speed Protection Using Mechanical DC Circuit Breakers," Power Delivery, IEEE Transactions on, vol. 30, no. 3, pp. 1383-1391, June 2015.

[17] A. Junyent-Ferré, P. Clemow, M. M. Merlin, and T. C. Green, "Operation of HVDC modular multilevel converters under DC pole imbalances," in Power Electronics and Applications (EPE'14-ECCE Europe), 2014 16th European Conference on. IEEE, 2014, pp. 1-10.

[18] A. Gustafsson, M. Saltzer, A. Farkas, and M. J. Hossein Ghorbani, Tobias Quist, "The new 525kV extruded HVDC cable system," $A B B$ Grid Systems, Technical Paper, 2014.

[19] S. Dennetière, H. Saad, and B. Clerc, "Setup and performances of the real-time simulation platform connected to the INELFE control system."

[20] G. Tang, Z. He, H. Pang, X. Huang, and X. p. Zhang, "Basic topology and key devices of the five-terminal DC grid," CSEE Journal of Power and Energy Systems, vol. 1, no. 2, pp. 22-35, June 2015.

[21] A. Beddard and M. Barnes, "HVDC cable modelling for VSC-HVDC applications," in PES General Meeting - Conference Exposition, 2014 IEEE, July 2014, pp. 1-5.

[22] ABB Switzerland Ltd., "Overvoltage protection - metal oxide surge arresters in medium voltage systems," 2011.

[23] G. Chaffey, P. D. Judge, and T. C. Green, "Energy requirements for modular circuit breakers in multiterminal HVDC networks," in HVDC 2016, International Conference on, CSEE, Shanghai. 